\title{
Sobre el pedido de informe del Relator Especial sobre Independencia de los Magistrados y Abogados (ONU) al Estado Argentino
}

On the request for a report from the Special Rapporteur on the Independence of Judges and Lawyers (UN) to the Argentine State

Sobre o pedido de informe do Relator Especial sobre Independência dos Magistrados e Advogados (ONU) ao Estado argentino

Sur la demande d'un rapport du Rapporteur spécial sur l'indépendance des magistrats et des avocats (ONU) à l'État argentin

应地方法官和律师独立问题特别报告员 (联合国)要求向阿 根廷提交报告。

\begin{tabular}{l|l} 
E. Raúl Zaffaroni & \\
& $\begin{array}{l}\text { Universidad de Buenos Aires, } \\
\text { Argentina }\end{array}$
\end{tabular}

Revista Derechos en Acción ISSN 2525-1678/ e-ISSN 2525-1686

Año 4/Nํ 13, Primavera 2019 (21 septiembre a 20 diciembre), 369-394

DOl: https://doi.org/10.24215/25251678e343

Recibido: 15/11/2019

Aprobado: 25/11/2019

Resumen: El autor analiza el autor analiza el pedido de informe emitido por el Relator Especial sobre Independencia de los Magistrados y Abogados, Dr. Diego García Sayán ante las denuncias efectuadas por diversas organizaciones no gubernamentales de la Argentina, con una mirada centrada en el fenómeno conocido como Lawfare o guerra judicial.

Palabras claves: independencia judicial- ONU- Lawfare

1 Profesor Emérito de la UBA. 
Abstract: The author analyzes the request for a report issued by the Special Rapporteur on the Independence of Judges and Lawyers, Dr. Diego García Sayán, in response to complaints made by various non-governmental organizations in Argentina, with a focus on the phenomenon known as Lawfare or judicial war.

Keywords: judicial independence- UN- Lawfare

Resumo: 0 autor analisa o pedido de informe emitido pelo Relator Especial sobre Independência dos Magistrados e Advogados, Dr. Diego García Sayán antes as alegações efetuadas por várias organizações não-governamentais da Argentina, com foco no fenômeno conhecido como Lawfare ou guerra judicial.

Palavras-chave: independência judicial - ONU - Lawfare

Résumé: L'auteur analyse la demande de rapport émise par le Rapporteur spécial sur l'indépendance des magistrats et des avocats, le Dr Diego García Sayán, suite aux allégations formulées par diverses organisations non gouvernementales en Argentine, en mettant l'accent sur le phénomène connu sous le nom de Lawfare (Guerre juridique) ou Guerre judiciare.

Mot-clés: indépendance judiciaire - ONU - Lawfare - Guerre juridique

摘要：作者分析了提交人分析的请求,该报告要求地方法官和律师 独立性特别报告员迭戈·加西亚・萨扬博士 (DiegoGarcíaSayán 博士) 在阿根廷各非政府组织提出指控之前进行报告, 重点是该现 象。被称为法律战争或司法战争。

关键字: 司法独立, 联合国, 法律 


\section{El pedido de informe al Gobierno Argentino del Relator Especial sobre Independencia de los Magistrados y Abogados de la Organización de Naciones Unidas ${ }^{2}$}

Excelentísimo

Señor Jorge Marcelo Faurie

Ministro de Relaciones Exteriores y Culto

1 de noviembre de 2019

Excelencia,

Tengo el honor de dirigirme a Usted en mi calidad de Relator Especial sobre la independencia de los magistrados y abogados, de conformidad con la resolución 35/11 del Consejo de Derechos Humanos.

En este contexto, quisiera señalar a la atención urgente del Gobierno de Su Excelencia la información que he recibido respecto a la presunta existencia de un Plan sistemático y estructural de amedrentamiento del Poder Judicial de la República de Argentina, que se refleja en los casos que se resumen a continuación. De acuerdo a dichas alegaciones dicho supuesto plan se estaría ejecutando por parte del Poder Ejecutivo por medio de una serie de actos concatenados, vinculados los unos a los otros estrechamente. Los alegados actos de intimidación y presión a los diversos órganos que componen el sistema judicial argentino, tales como el Ministerio Público y el Consejo de la Magistratura habrían socavado su independencia obstaculizando la posibilidad de una actuación imparcial en decisiones que afectan a los intereses del Poder Ejecutivo; asi como disciplinando a los magistrados que hubieran dictado resoluciones contrarias a la voluntad del Ejecutivo.

2 NdE: Se transcribe aquí íntegramente el pedido de informe. 
Según la información recibida:

Consejo de la Magistratura del Poder Judicial de la Nación

El Consejo de la Magistratura es un órgano permanente del Poder Judicial de la Nación, cuyas atribuciones incluyen la selección, suspensión y eventual remoción de los magistrados, y la administración del Poder Judicial. Está integrado por tres jueces del Poder Judicial, seis legisladores, dos representantes de los abogados, un representante del Poder Ejecutivo y un representante del ámbito académico y científico. El consejo se divide en cuatro comisiones: Comisión de Selección de Magistrados y Escuela Judicial; Comisión de Disciplina y Acusación, Comisión de Administración y Financiera y la Comisión de Reglamentación.

Según la información recibida, la coalición gobernante habría obtenido una mayoría política en el Consejo de la Magistratura, a partir de la designación como miembro del Consejo, del Diputado Pablo Gabriel Tonelli, en febrero del 2016. Por medio de dicha mayoría en el Consejo, el poder ejecutivo utilizaría la Comisión de Disciplina y Acusación para perseguir a los magistrados que dictan resoluciones contra sus intereses. Se habría también utilizado la Comisión de Selección de magistrados para la selección de determinados magistrados. Para este fin, presuntamente la Comisión paraliza los concursos que son ganados por postulantes no afines al gobierno; y traslada magistrados vinculados o cercanos al partido gobernante, sin respetar los requisitos establecidos en la legislación, tales como la competencia material y la jurisdicción territorial. De esta forma, estos magistrados son colocados en puestos clave sin cumplir los trámites establecidos, posibilitando, presuntamente, el control por parte del gobierno.

Según la información recibida, el remplazo transitorio o subrogancia de magistrados por medio de designaciones no conformes a la legislación se ha producido en numerosas 
ocasiones; y afecta las garantías de inamovilidad, intangibilidad e independencia de los magistrados. Las designaciones transitorias son realizados por el Consejo de la Magistratura para cubrir juzgados claves, como los Juzgados Federales con competencia electoral o los tribunales de máxima jerarquía nacionales como la Cámara Federal de Casación y los Tribunales Federales que tienen a su cargo el enjuiciamiento de los responsables de crímenes durante la dictadura.

La designación de dos jueces en la Corte Suprema de Justicia de la Nación por decreto

El 14 de diciembre de 2015, el poder ejecutivo resolvió por Decreto ${ }^{\circ}$ 83/2015 la designación de los jueces Carlos Fernando Rosenkrantz y Horacio Daniel Rosatti en la Suprema Corte de Justicia de la Nación Argentina.

Según la información recibida dichos nombramientos se habrían realizado sin respetar los requisitos del proceso de selección y nombramiento de jueces de la Corte Suprema establecido en la legislación (entre otros por lo dispuesto por el Decreto 222/2003), tales como las audiencias públicas, la participación de la sociedad civil o la aprobación del Senado de la Nación. Dicha designación sería, por tanto, unilateral, en condiciones precarias de legalidad y podría sugerir que dichos magistrados no estarían libres de conexiones o influencias políticas.

\section{El ataque a la Procuradora General de la Nación}

En junio 2012, la doctora Alejandra Magdalena Gils Carbó fue propuesta como precandidata al puesto de Procuradora General de la Nación por la ex Presidenta Cristina Fernández Kirchner. La doctora Gils Carbó fue nombrada Procuradora General de la Nación a través del decreto 1481/2012 y tomó posesión del cargo el 29 de agosto de ese año. 
Según la información recibida, la actual administración y otros actores solicitaron repetidas veces su renuncia e intentaron su destitución utilizando diversas estrategias para lograr su objetivo: presiones para que la Procuradora dejara el cargo; amenaza de vulnerar la estabilidad del Ministerio Público Fiscal; declaraciones sobre la intención de llevar a cabo reformas institucionales por Decreto de necesidad y urgencia; intentos de reformar la Ley Orgánica del Ministerio Público Fiscal; e inicio de acciones judiciales por parte de ONGs afines al gobierno nacional.

Dichas acciones supuestamente comenzaron durante la campaña electoral de 2015, y se habrían ejercido tanto por el Ejecutivo como por sus funcionarios mediante una intensa campaña mediática dirigida a desprestigiar a la Dra. Gils Carbó ya debilitar el Ministerio Público Fiscal. Según la información recibida las líneas editoriales del Grupo Clarín y La Nación habrían participado en dicha campaña.

Según la información recibida, la amenaza de vulnerar la estabilidad del Ministerio Público Fiscal se habría centrado en declaraciones aduciendo que la garantía de inamovilidad de la Procuradora General no tendría raigambre constitucional y que por ello el Gobierno podría removerla por medio de un decreto. El objetivo de dichas amenazas habría sido la de restar jerarquía y peso institucional a la Procuradora General en su relación con los demás poderes del sistema judicial.

Respecto a la intención de llevar a cabo reformas institucionales por medio de Decretos de necesidad y urgencia, se publicaron una serie de artículos periodísticos, según los cuales el Ejecutivo tendría la intención de realizar reformas para recortar las funciones del Ministerio Público, socavar su estabilidad y las inmunidades funcionales de sus miembros y retirar a su titular facultades para el ejercicio del gobierno del Ministerio. El 24 de diciembre de 2015, por medio de los decretos 256/2015 y 257/2015, se transfirió el 
Departamento de Interceptación y Captación de Comunicaciones del Ministerio Público Fiscal a la Corte Suprema de Justicia de la Nación.

Los intentos de reformar la Ley Orgánica del Ministerio Público Fiscal se tradujeron en un proyecto que se envió a la Cámara de Senadores, el cual establecía un plazo para el mandato del Procurador General de la Nación -en lugar de continuar como un puesto vitalicio-; y proponía la creación de procuradurías generales -tomando parte de las potestades del Procurador General. Según la alegación recibida el objeto de dicha reforma habría sido la de modificar la estructura del Ministerio Público Fiscal socavando la autonomía e independencia del órgano y particularmente anular la figura de la Procuradora Gils Carbó.

Finalmente, según la información recibida, dos asociaciones de abogados habrían llevado a cabo una tarea de hostigamiento hacia la labor de la Dra. Gils Carbó como Procuradora General a través de acciones judiciales, en particular dos interpuestas en 2017, con el objetivo de declarar inconstitucional el artículo 76 de Ley Orgánica del Ministerio Fiscal que establece que el Procurador General solo puede ser removido por las causales y mediante el procedimiento establecido en los artículos 53 y 59 de la Constitución Nacional. Ambas asociaciones solicitaron el archivo de las diligencias una vez que la Procuradora General Gils Carbó hubo anunciado su renuncia. La Procuradora General de la Nación renunció al cargo en noviembre de 2017.

La designación ilegal del Juez Culotta en la Competencia Electoral de la Provincia de Buenos Aires

Según la alegación recibida, el Consejo de la Magistratura habría manipulado la competencia en materia electoral en el Poder Judicial. Un ejemplo sería la subrogación, presuntamente ilegal, del magistrado Juan Manuel Culotta en la Competencia Electoral de la Provincia de Buenos Aires. 
Según la información recibida, el Consejo de la Magistratura por medio de la Resolución 1/2016 escindió la competencia material del Juzgado Federal de Primera Instancia $\mathrm{N}^{\circ} 1$ de La Plata y encomendó a dos juegos diferentes el ejercicio de una jurisdicción única. A partir de esta resolución se designó, por un lado, a un magistrado subrogante del mismo Juzgado para la materia Criminal y Correccional, y por otro, a la Dra. María Romilda Servini de Cubría para la materia electoral. Sin embargo, esta magistrada renunció a la subrogación en diciembre del 2016.

Según la información recibida, el Dr. Juan Manuel Culotta, Juez Federal del Juzgado Federal de Tres de Febrero de la Provincia de Buenos Aires, fue arbitraria y discrecionalmente seleccionado por el Consejo de la Magistratura para suplir a la Dra. Servini de Cubría. Esta designación conllevaba la jurisdicción en materia electoral del distrito electoral más importante del país en el momento de disputarse las elecciones nacionales del año 2017. La designación del Dr. Culotta en marzo del 2017, incrementó su competencia territorial a toda la provincia de Buenos Aires, otorgándosele competencia en materia electoral, para la cual no había concursado, y para lo cual su capacidad no había sido evaluada por los órganos públicos. Su designación tampoco había sido aprobada por el Congreso. Según la alegación recibida, el Dr. Juan Manuel Culotta poseería vínculos estrechos y de amistad con el presidente Macri, con su abogado personal, y especialmente con el Dr. Pablo Clusellas, Secretario Legal y Técnico de la Nación. Una vez realizados los comicios nacionales y el recuento de votos, el Dr. Juan Manuel Culotta, solicitó que no se le renovara dicha subrogación.

La designación ilegal del Juez Mahíques en la Cámara Federal de Casación Penal

Según la alegación recibida, el Dr. Carlos Mahíques siendo Juez de la Cámara Nacional de Casación en lo Penal y 
Correccional del Poder Judicial Nacional en Buenos Aires, solicitó licencia en diciembre de 2015 para ejercer como Ministro de Justicia de la Provincia de Buenos Aires. El Dr. Mahíques desempeñó el cargo desde el 11 de diciembre de 2015 hasta el 31 de mayo de 2016, fecha en la que presentó su renuncia para volver a su cargo en el Poder Judicial Nacional.

El 27 de abril del 2017, el Dr. Carlos Mahiques, solicitó al Consejo de la Magistratura Nacional ser designado en la Cámara Federal de Casación Penal -máximo órgano judicial penal- en razón de la vacante surgida después de la jubilación de uno de los miembros de dicha Cámara. Este cambio suponía un traslado no equivalente -ni en competencia material, ni territorial-, y no reunía los requisitos necesarios, tales como el concurso de antecedentes y oposición, la entrevista, la selección por el Poder Ejecutivo y la aprobación por el Senado de la Nación.

La "Comisión de Selección de Magistrados y Escuela Judicial" del Consejo de la Magistratura aprobó con gran celeridad el traslado -al día siguiente-. Posteriormente se remitió una solicitud para que la Cámara Federal de Casación Penal emitiera su opinión. El 28 de abril, la Cámara, mediante la Resolución $\mathrm{N}^{\circ}$ 218/17, rechazó por mayoría de sus miembros el traslado del Dr. Mahiques argumentando que existía un concurso ( $\mathrm{N}^{\circ}$ 281/2014) en su etapa final -el cual llevaba más de tres años en proceso- tendiente a cubrir las vacantes en ese Tribunal.

Sin embargo, y según la información recibida, el 4 de mayo, el Consejo de la Magistratura aprobó el traslado del Dr. Mahiques a la Cámara Federal de Casación Penal. El 5 de mayo la Cámara mostró su desacuerdo. Sin embargo, el 10 de mayo, el Poder Ejecutivo, con el refrendo del Ministro de Justicia mediante el Decreto 328/2017 -el cual no contaba con la preceptiva firma del Jefe de Gabinete de Ministros- resolvió el traslado definitivo solicitado por el 
juez Mahiques. Un año más tarde, el 10 de mayo de 2018, el Poder Ejecutivo ingresó el pedido para obtener el acuerdo del Senado, para el nombramiento del juez Mahiques en la Cámara Federal de Casación.

Según la información recibida, existirían vínculos entre el Dr. Mahiques y el gobierno provincial y el nacional. El hijo del Dr. Mahiques habría sido designado por el Presidente Macri como representante del Poder Ejecutivo ante el Consejo de la Magistratura y Subsecretario de relaciones con el Poder Judicial.

La alegada designación ilegal del Juez Leopoldo Bruglia en la Cámara Nacional de Apelaciones en lo Penal y Correccional Federal

Según la información recibida, el Dr. Leopoldo Oscar Bruglia fue designado Juez de Cámara de los Tribunales Orales en lo Criminal Federal de la Capital Federal en 1993, previa aprobación del Senado. El Sr. Bruglia desempeñó dicho cargo hasta noviembre de 2017, cuando mediante Resolución No 643/2016 del Consejo de la Magistratura se le otorgó una subrogancia en la Cámara de Apelaciones en lo Criminal y Correccional Federal. Dicha subrogancia tuvo lugar después de la suspensión del Juez Eduardo Freiler, magistrado de la Cámara de Apelaciones, quien había procesado al presidente Mauricio Macri en el marco de escuchas ilegales realizadas a opositores políticos, cuando era Jefe de Gobierno de la Ciudad Autónoma de Buenos Aires. Dicha subrogación se realizó sin especificar las razones de su selección, ni realizado los procedimientos constitucionales, legales y jurisdiccionales que la avalaran. Posteriormente, el Dr. Bruglia se dirigió al Consejo de la Magistratura solicitando su traslado definitivo a la Cámara de Apelaciones en lo Criminal y Correccional Federal.

El 6 de abril de 2018, se aprobó el traslado definitivo del Dr. Bruglia a la Cámara de Apelaciones en lo Criminal y 
Correccional Federal, Sala 1, de la Capital Federal, mediante el Decreto $n^{\circ}$ 278/2018. Dicho traslado se realizó sin cumplir los requisitos establecidos en la legislación relativa al procedimiento de designación de Jueces, tales como la aprobación del Senado, la validación de sus conocimientos y la celebración de un concurso público de antecedentes.

\section{El ataque a los jueces y abogados del Fuero Laboral}

Según la información facilitada, el Ejecutivo y miembros de su coalición política habrían realizado un ataque sistemático contra magistrados jueces del fuero laboral que dictan sentencias contrarias a los intereses gubernamentales, así como contra los abogados del fuero laboral. Estos ataques, presuntamente, se llevaron a cabo en sintonía con los principales medios de comunicación, quienes también tendrían intereses en otras áreas de la economía y, por ello, identifican al derecho laboral y a los jueces de dicho fuero como un obstáculo para sus intereses.

Intentos de destituir en forma arbitraria a magistrados que intervienen en cuestiones laborales

Según la información recibida, se habrían producido ataques contra magistrados del combustible laboral que han dictado resoluciones judiciales o sentencias a favor de trabajadores y/o sus organizaciones sindicales. Estos ataques se habrían manifestado en forma de solicitudes de destitución, amenazas de presentar dichas solicitudes y en procesos de estigmatización pública.

Según la información recibida, uno de estos ejemplos se produjo en el Juzgado de lo Contencioso Administrativo $\mathrm{N}^{\circ} 1$ de La Ciudad de La Plata en el contexto de un conflicto salarial docente. El magistrado Dr. Luis Federico Arias, que declaró la inconstitucionalidad del llamado a la conciliación obligatoria ordenada por el Poder Ejecutivo Provincial, fue denunciado por un diputado local, del mismo signo político 
que el Poder Ejecutivo Provincial y Nacional. A continuación, se producido un proceso de enjuiciamiento a dicho magistrado, en el cual tuvieron lugar, presuntamente, una serie de irregularidades. El magistrado fue suspendido y posteriormente destituido en agosto del 2018.

Según la información recibida, en abril de 2017, la jueza Dora Temis, a cargo del Juzgado Nacional del Trabajo $\mathrm{N}^{\circ} 59$ con asiento en la Ciudad de Buenos Aires, declaró admisible una medida cautelar presentada por la Unión de Docentes Argentinos (UDA) y ordenó cautelarmente al Ministerio de Trabajo que convocara una negociación colectiva nacional. A raíz de estos hechos, diversos representantes del gobierno la acusaron en los medios de comunicación de tener una actitud opositora e intencionalidad política.

Según la información recibida, en febrero de 2017, el Ministerio de Trabajo presentó ante el Consejo de la Magistratura un pedido de juicio político contra los jueces Enrique Arias Gibert y Graciela Marino que habían avalado la negociación colectivo del gremio de empleados bancarios; y habían exigido al Ejecutivo que se abstuviera de interferir en dicha negociación. El Ministerio solicitó la destitución de los jueces aduciendo un "mal desempeño, falta de idoneidad, negligencia grave, arbitrariedad, falta de imparcialidad e incumplimiento de la Constitución Nacional”. La denuncia fue desestimada hacia fines del 2017.

Según la información recibida, en diciembre de 2015, el Poder Ejecutivo Nacional disolvió, por decreto, la autoridad de aplicación de la Ley de Servicios de Comunicación Audiovisual (DNU 267/15379), lo que conllevó el despido de una gran cantidad de trabajadores, en razón a su adscripción política, según denunciaron los mismos. En uno de los casos judiciales que se iniciaron en relación a este despido, la Cámara Nacional de Apelaciones del Trabajo de la Capital Federal, Sala VI, entendió que parecía tratarse de un despido discriminatorio y ordenó la reincorporación 
precautoria de los trabajadores, mientras se tramitara el pleito por el que se requería se declarara la nulidad de dichos despidos. A raíz de tal decisión, el Poder Ejecutivo Nacional impulsó el "jury" de enjuiciamiento en el Consejo de la Magistratura contra los magistrados firmantes, el Juez Luis Raffaghelli y la Jueza Diana Cañal. La denuncia fue desestimada en mayo de 2018.

Expresiones del Ejecutivo en relación a los magistrados y abogados del fuero laboral

Según la información recibida, el 2 de junio de 2017, durante el aniversario del Colegio de Abogados de la Ciudad de Buenos Aires, el Presidente Macri expresó públicamente: "la mafia de la industria del juicio que le ha hecho un daño gigantesco a la Argentina"; así como que "el daño de los últimos meses, año y medio, diez mil millones de pesos de honorarios que se han distribuido a través de este mecanismo. Cada vez que uno de esos malos abogados, ligados a malos jueces laborales como Arias Gibert y Marino logran una sentencia, se condena a una pyme a cerrar".

Según la información recibida, a los pocos días de esas expresiones, el 12 de junio de 2017, durante un acto en la Casa de Gobierno, el Presidente Macri volvió a llamar a "enfrentar y terminar con la mafia de los juicios laborales". El ministro de Trabajo, Empleo y Seguridad Social de la Nación, Jorge Triaca, también señaló en esas fechas que "el abuso del sindicalismo por el cual algunos viven o generan una industria del juicio" sería "una de las principales causas de involución en la Argentina".

La manipulación de Fiscales en la causa "Correo Argentino SA s/ Concurso Preventivo"

Según la alegación recibida, en 1997 el Grupo Macri adquirió la concesión de la empresa "Correo Argentino SA" a través del Grupo SOCMA donde el Presidente Macri ostentaba el 
cargo de gerente general. En el año 2001 la empresa entró en concurso de acreedores y en 2003 el Estado rescindió el contrato de concesión. La deuda del Grupo con el Estado en concepto de canon ascendía a casi 300 millones de pesos, que conforme la ley de convertibilidad, vigente a la fecha, equivalía a US $\$ 300$ millones.

En el año 2016, se logró en el marco de una causa judicial en el Juzgado Nacional de lo Comercial $\mathrm{N}^{\circ} 9$ de la Capital Federal, un acuerdo de pago entre el Estado Nacional y el Grupo. El grupo económico ofertó y el Estado aceptó en pagar 300 millones de pesos -no dólares estadounidenses-, lo que no tenía en cuenta la devaluación de la moneda argentina, ni los intereses por mora; además el pago se aplazaba en cuotas hasta el año 2033. Para homologar el acuerdo era necesario la aprobación del Ministerio Público Fiscal. La fiscal, la Dra. Gabriela Boquín, consideró "abusiva" la oferta del grupo empresarial. Se opuso a su homologación, y generó la caída del acuerdo, que entendía era perjudicial para el Estado argentino. El dictamen fiscal de Cámara establecía que se debía actualizar el monto de la deuda, lo que la incrementaba a una cifra cercana a los \$4.700 millones de dólares estadounidenses.

La Justicia Federal Penal de la Ciudad Autónoma de Buenos Aires inició una instrucción penal, por medio del Fiscal Dr. Juan Pedro Zoni, para determinar si se pudo haber cometido algún delito en el trámite del acuerdo entre el ejecutivo y la compañía. Como resultado de la investigación se dio un pedido de imputación del Presidente Macri, del Ministro de Comunicación, Sr. Oscar Aguad, y del representante jurídico del Estado Nacional, Dr. Juan Moccoroa.

Según la información recibida, en abril del 2018, el Fiscal Dr. Zoni -quien se encontraba investigando los libros contables de las sociedades del Grupo para determinar si se desviaron fondos de Correo Argentino SA a otras compañías del holding del Grupo durante el concurso de acreedores- fue 
desplazado de su cargo a otro de menor importancia por el Procurador interino, Eduardo Casal, presuntamente bajo el argumento de haber sido considerado en la Fiscalía en forma "Transitoria". Según la información recibida, dicho traslado fue consecuencia de su obrar independiente, y del procesamiento del Presidente Macri. El fiscal designado para sustituir al fiscal Zoni interinamente, fue el Dr. Gerardo Pollicita, quien haya trabajado para el presidente Macri, cuando este ostentaba el cargo de Presidente del Club Boca Juniors.

Según la información recibida, se desarrollaron diversas estrategias para apartar a la Fiscal Gabriela Boquín del caso, y desgastarla mediáticamente. Así, los abogados de Correo Argentino SA intentaron retirarla del manejo del expediente, pero el Juzgado de Primera Instancia y la Cámara Nacional de Apelaciones en lo Comercial de la Capital Federal, la ratificaron en el cargo. Ante esta resolución, el grupo empresarial presentó un recurso extraordinario ante la Corte Suprema de Justicia de la Nación. El recurso fue denegado en diciembre de 2018, por lo que se intentó el recurso extraordinarísimo de "Queja" ante el Supremo Tribunal, para que este se expidiera sobre la petición.

En cuanto al desgaste mediático, en febrero de 2017, el Consejero de la Magistratura y Diputado Nacional por la coalición oficialista de "Cambiemos" Pablo Tonelli, en declaraciones radiales criticó las aptitudes de la fiscal Gabriela Boquín, y manifestó que su dictamen "dice cualquier cosa, si nos vamos a basar en lo que dice estamos mal ... Ella es la que no reúne las aptitudes necesita para el cargo". En las mismas fechas, la Senadora Nacional y jefa del partido gobernante, Laura Rodríguez Machado, dijo que "Gabriela Boquín inventa una deuda que no es la que dice la norma legal, la que dice el juez y a partir de ahí se genera este escándalo ... Una cuenta que se le cruza por la cabeza a ella y que hace parecer que el padre del presidente tiene privilegios", agregó. 


\section{Alegado contexto de injerencia en el Poder Judicial}

\section{Provincia de Buenos Aires}

En diciembre de 2016, el Dr. Julio Marcelo Conte Grand fue nombrado Procurador General de la Suprema Corte de Justicia de la Provincia de Buenos Aires, función de máxima autoridad del Ministerio Público de la Provincia, incluyendo la jefatura de quienes deben investigar las denuncias contra los funcionarios del actual gobierno provincial y sus opositores. Según la información recibida, el Procurador sería una persona cercana a la Gobernadora de la Provincia de Buenos Aires, la Lic. María Eugenia Vidal, y al Presidente Macri. De hecho, la Gobernadora nombró al Sr. Conte Grand en diversos puestos en el pasado. En 2012, le designó Procurador General del Poder Judicial de la Ciudad Autónoma de Buenos Aires, a propuesta del Presidente Macri; en 2015 le nombró Secretario de Legal y Técnica de la Provincia de Buenos Aires, al día siguiente de su Asunción en el cargo de Gobernadora; y en diciembre de 2016, le designó como Procurador de la Provincia de Buenos Aires.

Según la información recibida, también en esta provincia, el Dr. Luis Federico Arias, titular del Juzgado en lo Contencioso Administrativo $\mathrm{n}^{\circ} 1$ de La Ciudad de La Plata, dependiente de la Suprema Corte de la Provincia de Buenos Aires, habría sido víctimas de un proceso de enjuiciamiento político y destituido por el contenido de sus sentencias. En este sentido, se le habría juzgado por un tribunal conformado por legisladores afines al Poder Ejecutivo Provincial, en base a una denuncia aparentemente extinguida.

Según la información recibida, el Dr. Carlos Rozansky, titular del Tribunal Oral Federal en lo Criminal No 1 de La Plata, fue víctima de una campaña mediático-política de desprestigio, la cual incluyó denuncias en el Consejo de la Magistratura, y ataques de abogados defensores de violadores de derechos humanos, entre otros, lo que desencadenó su renuncia. Dicha 
renuncia fue aceptada en noviembre de 2016. El magistrado Rozansky fue el primer magistrado que tipificó jurídicamente como genocidio lo acaecido en la República Argentina entre los años 1976 y 1983.

\section{Tarifas de Servicios Públicos}

Según la información recibida, los magistrados que cuestionaron la constitucionalidad del aumento de las tarifas de servicios públicos esenciales dispuesto por el Poder Ejecutivo Nacional en 2016 fueron víctimas de ataques, intimidaciones públicas y pedidos de enjuiciamiento.

Según la información recibida, la magistrada que sufrió las intimidaciones de una manera más intensa y a quien se utilizó para lograr el disciplinamiento de los jueces que dictaban resoluciones para "impedir" los aumentos tarifarios fue la Dra. Martina Forns, titular del Juzgado de Primera Instancia en lo Civil, Comercial y Contencioso Administrativo Federal $\mathrm{n}^{\circ} 2$ de San Martín, Provincia de Buenos Aires. En agosto de 2016, la Dra. Forns en el marco de un proceso en el que se impugnaron las resoluciones que habilitaron los aumentos tarifarios, dictó una medida cautelar por la que suspendía los aumentos en la tarifa de la energía eléctrica en el país. A partir de ese momento, la magistrada comenzó a sufrir diversas intimidaciones públicas, incluidas de funcionarios del poder ejecutivo, tanto a través de la prensa como a través de twitter; identificándola como militante del partido político opositor, y acusándola de falta de independencia, imparcialidad y conocimiento jurídico. Dos semanas después de haber dictado la sentencia, una granada de mano fue hallada en un contenedor cercano a la casa de la magistrada. En paralelo a estas situaciones, el cónyuge de la magistrada, el Dr. Gabriel Macaggi, habría sido despedido como abogado de la Inspección General de Justicia, dependiente del Ministerio de Justicia y Derechos Humanos de la Nación. 
En septiembre de 2016, el Consejo de la Magistratura recibió una solicitud de enjuiciamiento a la Dra. Forns, por parte de un dirigente político, en base a un "mal desempeño en sus funciones, ignorancia inexcusable del derecho y falta de equilibrio emocional evidenciado con la reacción que tuvo al conocer el fallo de la Corte Suprema que revocó la decisión". El Consejo de la Magistratura tuvo la denuncia abierta durante más de un año, a pesar de que la misma se basaba en el contenido de una resolución judicial. A finales de 2017 se procedió al archivo de la misma.

$\underline{\text { Alegado ataque al Juez Federal de Dolores Dr. Alejo Ramos }}$ $\underline{\text { Padilla }}$

El Juez de Instrucción Federal de Dolores, el Dr. Alejo Ramos Padilla tiene a su cargo una causa judicial (Causa $\mathrm{N}^{\circ}$ FMP 88/2019, caratulada "D'Alessio, Marcelo Sebastián s/ asociación ilícita y otro") en la que se investiga una presunta red de espionaje ilegal y extorsión, con posibles conexiones con funcionarios públicos - fiscales, jueces federales y provinciales, y funcionarios del poder ejecutivo y periodistas.

Según la información recibida, la investigación llevada a cabo por el Juzgado Federal de Dolores generó una fuerte reacción negativa del Gobierno Nacional, que habría buscado desacreditar al magistrado y restarle apoyo institucional.

El 13 de marzo de 2019, el Juez Ramos Padilla compareció ante la Comisión de Libertad de Expresión de la Cámara de Diputados de la Nación, en relación a la investigación de esta causa. Dos días más tarde, el Ministro de Justicia Germán Garavano solicitó al Consejo de la Magistratura que se le abriera una investigación al Juez Ramos Padilla por violación de sus obligaciones de imparcialidad y reserva y que se iniciara el trámite de su destitución, al haber realizado ante la Comisión una exposición "insólitamente extensa". La denuncia contra el Juez Ramos Padilla quedó radicada ante la Comisión de Disciplina y Acusación del Consejo de la Magistratura y permanece abierta. 
Según la información recibida, junto con esta solicitud y varias declaraciones en medios de comunicación, el Poder Ejecutivo y miembros del partido oficialista impulsaron una campaña de desprestigio y persecución contra el juez Ramos Padilla. Así el Dr. Ramos Padilla fue acusado de ser un juez "militante" y "Kirchnerista". El 17 de marzo, el Presidente Macri declaró en un programa de televisión que Ramos Padilla "no es un juez que actúe con ecuanimidad", que "no es la primera vez, Ramos Padilla ya ha hecho varias así", y que esperaba "que el Consejo [de la Magistratura] evalúe con todas las pruebas si hay que destituirlo".

El 23 de abril, la Cámara Federal de Mar del Plata confirmó al Juez Ramos Padilla en esta causa sobre presunto espionaje ilegal y extorsión y rechazó una recusación del fiscal federal Carlos Stornelli, imputado en el caso. Según la Cámara, el Poder Ejecutivo habría denunciado al juez sin argumentos serios para pedir su destitución. Los jueces de la Cámara Federal sostuvieron que “(...) en el caso de autos la comparecencia del Dr. Ramos Padilla ante una entidad oficial como la Comisión de Libertad de Expresión de la Cámara de Diputados de la Nación, el aporte en ese ámbito público de datos del expediente que en su mayoría ya eran de conocimiento periodístico y las precisiones que fijara al respecto, sumado a la calidad de funcionario público de uno de los involucrados en las conductas investigadas (...) no alcanzan a evidenciarde una actitud de parcialidad procesal en perjuicio del recusante que autoricen su apartamiento".

Según la información recibida, la solicitud de juicio político contra el Juez Ramos Padilla habría supuesto un intento de influir y obstaculizar una causa judicial de relevancia, dado que no habría ningún argumento para justificar un "mal desempeño", "negligencia grave", "manifiesta arbitrariedad" o "incumplimientos reiterados de la Constitución" que diera lugar a la destitución, tal y como lo requiere la legislación argentina. 
Teniendo en cuenta la información y alegaciones recibidas, quisiera expresar mi preocupación sobre las mismas. Los supuestos hechos incluirían presuntos actos de amenaza, intimidación y presión a magistrados y magistradas, fiscales y abogados y abogadas, incluyendo: la manipulación del Consejo de la Magistratura; la selección, designación, traslado y subrogación de jueces y juezas sin tener en cuenta las garantías establecidas en los estándares internacionales; la intimidación contra la Procuradora General y fiscales; los ataques contra jueces y juezas y fiscales cuyas actuaciones no responderían a los intereses del poder ejecutivo; campañas mediáticas contra jueces y juezas, fiscales y abogados y abogadas; y los procesos de sustitución, suspensión y destitución de jueces y juezas sin respetar los requisitos establecidos en los estándares internacionales, entre otras actuaciones.

En relación con las alegaciones arriba mencionadas, sírvase encontrar adjunto el Anexo de referencias al derecho internacional de los derechos humanos, el cual resume los instrumentos y principios internacionales pertinentes.

Es mi responsabilidad, de acuerdo con el mandato que me ha sido otorgado por el Consejo de Derechos Humanos, intentar clarificar las alegaciones llevadas a mi atención. En este sentido, estaría muy agradecido de tener su cooperación y sus observaciones sobre los asuntos siguientes:

1. Sírvanse proporcionar cualquier información o comentario adicional en relación con las alegaciones arriba mencionadas.

2. Sírvanse proporcionar información sobre las medidas adoptadas para asegurar la autonomía efectiva del Consejo de la Magistratura y su independencia de los poderes ejecutivo y legislativo.

3. Sírvanse proporcionar información sobre las medidas adoptadas para asegurar que los procesos de selección y nombramiento en el Consejo de la Magistratura sean transparentes y participativos y que se cuenta con garantías para evitar la utilización de criterios políticos en dichos nombramientos. 
4. Sírvanse proporcionar información sobre las medidas adoptadas para asegurar que en los procedimientos disciplinarios que se realicen en el Consejo de la Magistratura, los jueces y juezas acusados y acusadas disfruten de todas las garantías procesales establecidas en el artículo 14 del Pacto Internacional de Derechos Civiles y Políticos; así como que las decisiones que se adopten están debidamente motivadas y sujetas a recurso ante un tribunal competente.

5. Asimismo, sírvanse proporcionar información sobre las medidas adoptadas para asegurar que la Comisión de Disciplina y Acusación no pueda ser instrumentalizada como una instancia para sancionar a magistrados y magistradas en razón de las sentencias que hayan dictado.

6. Sírvanse proporcionar información sobre las medidas adoptadas para asegurar que la independencia de la judicatura es respetada por las instituciones gubernamentales; y que los jueces pueden actuar sin restricciones, presiones, amenazas o intromisiones indebidas.

7. Sírvanse proporcionar información sobre las medidas adoptadas para asegurar que el procedimiento de selección y nombramiento de los jueces se basa en criterios objetivos establecidos previamente por ley o por la autoridad competente; que las decisiones relativas a la selección y a las carreras de los jueces se basan en el mérito, en particular las calificaciones, aptitudes y capacidades de los candidatos y candidatas, así como su integridad, sentido de independencia e imparcialidad.

8. Sírvanse también proveer información sobre las medidas adoptadas para asegurar que los concursos o procedimientos de selección y nombramientos de jueces no son evadidos u obviados por medio de traslados, remplazos transitorios o subrogaciones de otros magistrados y magistradas; que dichos traslados, remplazos o subrogaciones cumplen con los requisitos establecidos en los estándares internacionales; y que sean utilizados de de manera excepcional. 
9. Sírvanse proporcionar información sobre las medidas adoptadas para garantizar la permanencia en el cargo de los jueces por los establecidos establecidos, su independencia y su seguridad, así como una remuneración, pensiones y condiciones de servicio y de jubilación adecuadas.

10. Asimismo, provean información sobre las medidas adoptadas para garantizar la inamovilidad de los jueces, tanto de los nombrados mediante decisión administrativa como de los elegidos, hasta que cumplan la edad para la jubilación forzosa o expire el período para el que hayan sido nombrados o elegidos, cuando existan normas al respecto; y para asegurar que los ascensos de los jueces se basan en factores objetivos, especialmente en la capacidad profesional, la integridad y la experiencia.

11. Sírvanse proveer información sobre las medidas adoptadas para asegurar que toda acusación o queja formulada contra un juez por su actuación judicial y profesional se tramitará con prontitud e imparcialidad con arreglo al procedimiento pertinente; que los jueces solo podrán ser suspendidos o separados de sus cargos por incapacidad o comportamiento que los inhabilite para seguir desempeñando sus funciones; y que todo procedimiento para la adopción de medidas disciplinarias, la suspensión o la separación del cargo se resolverá de acuerdo con las normas establecidas de comportamiento judicial.

12. Sírvanse proporcionar información sobre las medidas adoptadas para asegurar que el o la Procuradora general de la Nación, y los y las fiscales puedan ejercer sus funciones profesionales sin intimidación, amenazas, hostigamiento, o injerencias indebidas.

13. Finalmente, sírvanse proporcionar información sobre las medidas adoptadas para asegurar que los abogados puedan desempeñar sus funciones profesionales sin intimidaciones, obstáculos, acosos o interferencias indebidas. 
Esta comunicación y toda respuesta recibida del Gobierno de su Excelencia se harán públicas a través del sitio web de comunicaciones en un plazo de 60 días. También estarán disponibles posteriormente en el informe que se presentará al Consejo de Derechos Humanos.

A la espera de su respuesta, quisiera instar al Gobierno de su Excelencia a que adopte todas las medidas necesarias para proteger los derechos y las libertades de la(s) persona(s) mencionada(s) e investigar, procesar e imponer las sanciones adecuadas a cualquier persona responsable de las violaciones alegadas. Quisiera asimismo instarle a que tome las medidas efectivas para evitar que tales hechos, de haber ocurrido, se repitan.

Tengo la intención de expresar públicamente mis preocupaciones en un futuro cercano, ya que considero que las informaciones recibidas son suficientemente fiables para indicar que existe un asunto que justifica una atención inmediata. Además, considero que la opinión pública tiene que ser informada sobre las implicaciones potenciales relacionadas con las alegaciones arriba mencionadas. El comunicado de prensa indicará que he estado en contacto con el Gobierno de Su Excelencia para aclarar las cuestiones relevantes.

Acepte, Excelencia, la expresión de mi más distinguida consideración.

Diego García-Sayán Relator Especial sobre la independencia de los magistrados y abogados

\section{Comentario}

El llamado lawfare o guerra judicial no es un invento argentino ni mucho menos, pero fue calurosamente adoptado como instrumento de lucha política en nuestro país por la administración 2015-2019. 
Como es sabido, el lawfare es una metodología que requiere la coautoría de los medios de comunicación monopólicos y de jueces. Los medios hegemónicos argentinos son los que han encubierto a esa administración y contribuyeron fundamentalmente a su encumbramiento, de modo que, por descontado, se prestaron gustosamente al juego. Pero no todos los jueces estuvieron dispuestos a servir de instrumento de lucha política, pese a que siempre es tentadora la promesa de fama publicitaria y son alentadores los gestos de simpatía de la cúpula de la administración.

Quienes prefirieron resistir los cantos sirenaicos del estrellato judicial pasaron a la categoría de jueces molestos para la administración. Más aún, algunos fueron considerados obstáculos y, por ende, a la administración se le hizo necesario quitarlos de su camino para dejar el campo libre a sus estrellas judiciales.

También es sabido que la administración 2015-2019, desempeñó el tristísimo papel de agente del poder financiero transnacional, contrayendo una deuda sideral en cortísimo tiempo, mediante un descarado procedimiento de fuga de divisas de capitales golondrinas. En definitiva, se trató de una maniobra de administración fraudulenta de inmensas dimensiones, que precipitó al país en una virtual situación de quiebra, aunque se prefiera eludir esa palabra usando otros eufemismos.

Se puso en marcha de esta manera la espiral del desastre: reducción presupuestaria (ajuste), menor recaudación, más ajuste. Esta espiral requiere también que nadie obstaculice las consecuencias del ajuste, en especial las que recaen sobre los trabajadores.

Nadie ignora que en la Argentina tenemos un sindicalismo fuerte y que, pese a todas las críticas que puedan formulársele para desprestigiarlo, conserva un alto nivel de organización y sentido común, harto ejemplar en nuestro continente.

Para neutralizar ese obstáculo al avance de la espiral del desastre se hace necesario que el lawfare avance también contra los jueces del trabajo de nuestro tradicional fuero laboral, cuyo 
origen se remonta a la negativa de la Corte Suprema de nuestra vieja República oligárquica a tomarle juramento a sus pioneros.

Los jueces del trabajo de larga trayectoria en el fuero también se tornaron molestos y, el titular del ejecutivo, en un acto de impaciencia -dejando escapar las palabras más rápido que el pensamiento- se atrevió a reclamar públicamente jueces propios y a calificar como mafia a los abogados laboralistas. En consecuencia, comenzó también una persecución contra jueces del trabajo en razón de sus sentencias.

Es la primera vez en toda nuestra historia judicial que se persigue a jueces por el contenido de sus sentencias, lo que fue acompañado por decisiones de los jueces complacientes carentes de toda base jurídica. A eso se sumó la inexplicable y turbia relación de éstos con agentes de inteligencia, hasta llegar al escándalo público.

Se multiplicaron los procesamientos y las prisiones preventivas con pruebas y hasta tipificaciones insólitas. Se enunciaron como doctrina argumentos jurídicamente disparatados. Se movieron jueces como piezas de ajedrez para componer tribunales poco menos que ad boc. Desde la vuelta a la Constitución en 1983, jamás una administración había osado ir tan lejos en la manipulación de jueces y, menos aún, hacerlo con semejante grado de desfachatez.

Será difícil recomponer la cultura judicial, pues ha hecho cundir al criterio de decido lo que quiero en la medida de mi poder, los argumentos no cuentan. Afortunadamente, esto involucra a una minoría de jueces, pero el riesgo de descomposición cultural en el cuerpo judicial no puede ignorarse.

El Relator Especial de la ONU ha dado curso a la denuncia de estos hechos y en términos claros solicita explicaciones a la administración. Se trata de un paso importante para reforzar la cultura judicial, pues al menos pone de manifiesto que desde el mundo se observan estas conductas desviadas, que tarde o temprano dejan de ser tan impunes como la soberbia del poder puede hacer alucinar en algún momento. 
No merece la cultura jurídica argentina esta vergüenza. Pese a todas las enormes dificultades de nuestra accidentada historia política, hemos consolidado un alto nivel jurídico no sólo en lo académico sino también en la jurisprudencia. El desprecio que por todo esto ha demostrado la administración 2015-2019 sólo es comparable con el que puso de manifiesto respecto de la soberanía nacional, aunque, en el fondo, no se trata más que de dos caras de la misma moneda. 